\title{
EL PRESTIGIO DE LA BELLEZA Y Donde NADIE Me esPere de Piedad BONNETT: DOS BILDUNGSROMAN COLOMBIANOS*
}

\author{
EL PRESTIGIO DE LA BELLEZA AND DONDE \\ NADIE ME ESPERE By Piedad Bonnett: two \\ Colombian BildungsRoman
}

\footnotetext{
* Cómo citar este artículo: Rengifo Muñoz, A. (2021). El prestigio de la belleza y Donde nadie me espere de Piedad Bonnett: dos Bildungsroman colombianos. Estudios de Literatura Colombiana 49, pp. 175-192. DOI: https://doi.org/10.17533/udea.elc.n49a10

1 https://orcid.org/ 0000-0002-8232-5815 rengi1a@cmich.edu

Central Michigan University, United States
}

Editores: Andrés Vergara Aguirre, Christian Benavides Martínez

Recibido: 06.02.2021

Aprobado: 21.05.2021

Publicado: 30.06 .2021

Copyright: (2021 Estudios de Literatura Colombiana. Este es un artículo de acceso abierto distribuido bajo los términos de la Licencia Creative Commons AtribuciónNo comercial - Compartir igual 4.0 Internacional

\section{Alejandra Rengifo Muñoz ${ }^{1}$}

Resumen: Bonnett es conocida por su trayectoria poética a nivel nacional e internacional. En su novelística retrata la condición humana desde una perspectiva personal e íntima donde prima el aspecto psicológico. Dos de sus novelas, El prestigio de la belleza y Donde nadie me espere, pueden ser consideradas como Bildungsroman gracias a la amplia categorización que da este género teórico, pues muestran cómo los protagonistas llevan a cabo una búsqueda de sí mismos a través de un proceso fenomenológico y psicológico que los modifica y los forma como individuos, logrando así una de las premisas de este tipo de novelas: su autodescubrimiento y autoformación.

Palabras clave: Bildungsroman; belleza; espíritu; voluntad; autoformación.

Abstract: : Bonnett is known for her poetic career at national and international level. In her novels she portrays the human condition from a personal and intimate perspective where the psychological aspect stands out. Two of her novels, El prestigio de la belleza and Donde nadie me espere, can be considered Bildungsroman, thanks to the ample categorization given by this theoretical genre, as they show how the protagonists carry out a search for themselves through a phenomenological and psychological process that modifies and shapes them as individuals, thus achieving one of the premises of this type of novels: their self-discovery and self-formation.

Key words: Bildungsroman; beauty; spirit; volition; selfgrowth. 
Piedad Bonnett es una de las poetas colombianas más reconocidas en la actualidad. Si bien "se distingue en su obra lírica por la articulación de discursos donde el signo de la cultura permanece como una referencia siempre viva, pero permeable y proteica" (Cervera Salinas, 2014, p. 69), donde "la soledad, el amor, el desamor y el olvido son formas transparentes de ese mundo cotidiano” (Motato, 2013, p. 38), y la ironía, los recuerdos de infancia, la ensoñación y la situación del país, entre otros, son temas centrales que también se encuentran en su narrativa. Dos de sus narraciones, El prestigio de la belleza (2010) y Donde nadie me espere (2018), son novelas que hacen eco del Bildungsroman, también llamadas novelas de autoformación. Estos textos forman parte de una categoría específica en la literatura colombiana pues reafirman un estilo narrativo en el cual lamentablemente "los análisis y las críticas sobre estas obras son escasas en Colombia" (Rosas Consuegra, 2017, p. 24), aunque sí ha sido "muy usado por las autoras colombianas a partir de los años setenta"(p. 23). Teniendo en cuenta lo anterior, este artículo estudiará cómo el tema de ambas novelas las clasifica dentro del género teórico del Bildungsroman, y cómo su autora va más allá de narrar el proceso de autoformación de los personajes por medio de una narración filosófica-psicológica.

\section{El Bildungsroman o la novela de autoformación}

El Bildungsroman es un género teórico que ha sido trabajado extensivamente en la literatura mundial y muy particularmente en la europea. ${ }^{1}$ Este no se asienta en los estudios literarios hasta los 1950, aunque en 1910 el termino se da a conocer fuera de Alemania, su país de origen, con una entrada en la Encyclopedia Britannica, hecho que ayuda a su descubrimiento en los círculos académicos de Europa. Es más, gracias a la definición dada por la Encyclopedia de ser un tipo de novela que "has [as] its main theme the formative years or spiritual education of one person" (Boes, 2006, p. 231), su uso se vuelve una designación práctica para cualquier novela de este tipo. Mientras en Gran Bretaña se personaliza el género, en Francia se "nacionaliza" con la ideología de que toda novela que sea sobre formación personal o de aprendizaje es Bildungsroman, pues

Término acuñado en el siglo xix por el filósofo y sociólogo alemán Wilhelm Dilthey, que con el tiempo ha logrado convertirse en un concepto literario amplio, maleable donde la falta de consenso respecto a una definición que lo uniformice le ha abierto la puerta a la pluralidad teórica del mismo. Sus orígenes datan de 1870 cuando Dilthey lo usó por primera vez en una biografía sobre el filósofo y teólogo alemán Friedrich Schleiermacher; posteriormente lo popularizó en 1906 con éxito en su estudio Poesía y experiencia. Esta definición sigue los parámetros conceptuales que se tiene en Alemania sobre la educación, según los cuales todos aquellos procesos que son educativos (esos que se dan tanto en la escuela como en la familia, en los campos de verano, con los padres) también son educación (Danner, 1994, p. 3); por ende, la formación de un ser humano empieza desde la Bildung, es decir, los primeros seis años de la educación primaria de los estudiantes. 
[...] el término alemán, extranjerismo que producía oscuridad semántica, conciencia de ajenidad, de molesta deuda o cuando menos de lo primero, fue traducido por las expresiones roman d'apprentissage o roman de formation, denominaciones que alcanzaron amplio eco en el resto de países de habla neolatina (Rodríguez Fontela, 1996, p. 29).

En ambos países, y los que siguieron el ejemplo, acomodaron el género a lo que sus propias producciones literarias habían hecho, pues resultaba ser una categorización válida y necesaria de muchas maneras. Sin embargo, los alemanes, padres legítimos del término, han conservado su estricta definición debido a que muchos académicos "often contend that the genre is inextricably tied to German concepts of culture and nationhood, and that the very term 'Bildung' (culture, education, formation) implies the cult of the inner life which has marked modern Germany for better and for worse" (Cole, 2007, párr. 5). Este modelo clásico remite a la ideología pedagógica alemana holística que defiende los procesos de aprendizaje en los que el mundo y la vida son los maestros, y el individuo se puede "autoformar" a través de sus experiencias. No obstante, con el tiempo los académicos y la producción de este tipo de narraciones se han encargado de expandir las diferentes características que puede tener una novela para ser considerada Bildungsroman, entre las que sobresalen aquellas que hablan de cambio, desarrollo, madurez.

Por tanto, dentro del caleidoscopio de opciones que han surgido de este subgénero, hay una definitoria que hace del Bildungsroman una teoría aún más heterogénea, según la cual existen Bildungsroman femeninos o masculinos. Se abre así una brecha interesante con esta diferenciación, pues la mujer ocupa un espacio y se ubica en su propia categoría, lo cual la instila a narrar su crecimiento desde su visión del mundo, que es distinta a la de su contraparte masculina. Si bien algunas se traslapan, cada uno tiene sus propias características, de manera que los Bildungsroman escritos sobre personajes femeninos tratan temas que afligen al género femenino al otorgarles voz y agencia que inicialmente eran solo para los hombres. Y los escritos sobre personajes masculinos hacen lo propio. Algunas de las discrepancias son sutiles, pero otras son radicales. De acuerdo con lo anterior, en el Bildungsroman masculino,

[...] el individuo se verá obligado a resolver los conflictos que surgen entre el sujeto y el entorno. Dichos conflictos no se presentan como obstáculos en su formación, sino que se configuran como etapas necesarias dentro de un proceso de desarrollo, que culminará con la madurez del personaje (Irigaray citado en Reyes Ferrer, 2018, párr. 2). 
Se debe recordar que estos conflictos son resultado de la sociedad y cultura anfitrionas del sujeto. Al emprender ese viaje emocional y espiritual que implica el autodescubrimiento, que a veces es hecho de manera simbólica, el protagonista lleva a cabo su búsqueda in situ, y en otras ocasiones es literalmente físico, imprimiéndole una mayor importancia al hecho de madurar en un mundo lleno de retos. Dicho viaje implica una soledad que conlleva el enfrentamiento con lo que el sujeto vive, lo cual contribuye a la complejidad de la historia. Es el caso de Donde nadie me espere, cuyo protagonista, Gabriel, se encuentra solo, buscando un centro, su verdad, en medio de una sociedad que lo ha mancillado siempre. De hechos como el anterior se derivan nuevas características del género, entre ellas la presencia de un conflicto espiritual de autoformación que el personaje experimenta y un ejercicio de autoconcientización. Tanto la concientización y el conflicto espiritual del sujeto del Bildungsroman presentan estrecha relación con los pensamientos filosóficos de Georg Wilhelm Friedrich Hegel y Arthur Schopenhauer sobre la fenomenología del espíritu. Si bien con ello se traza una complejidad mayor de lo que es el Bildungsroman, también se abre una puerta de análisis interesante en cómo se ven reflejados en los dos textos de Piedad Bonnett. Antes de hablar sobre estos aspectos, es necesario detenerse en el Bildungsroman y entender mejor la habilidad de Bonnett en la confección de dos novelas que caben cada una en un Bildungsroman de cada género.

Se ha dicho que el Bildungsroman masculino comparte varias de las características mencionadas anteriormente con su contraparte femenina, por ejemplo, que son novelas de crecimiento, de autoformación, de descubrir el mundo y tratar de encajar en la sociedad; pero en lo que respecta al Bildungsroman femenino, se aprecian aspectos muy acordes con la naturaleza de la mujer, con sus obstáculos, necesidades y luchas. El tipo de Bildungsroman escrito por mujeres y sobre mujeres se encuentra con que, aparte de experimentar las particularidades anteriores, la protagonista debe enfrentarse y sobrepasar las expectativas sociales a las que su género está sujeto. Entre las más destacables se hallan el matrimonio, la maternidad, la subordinación a un marido que pasa a tomar el lugar del padre en su cosmos, y ser el ángel del hogar. Estas normas se convierten en el Bildungsroman femenino en medidas para transgredir, pues "la ficción femenina se distingue de la masculina en que el proceso de desarrollo de la protagonista suele ser menos directo y más con- 
flictivo", y generalmente "la mujer aspira a alcanzar su autonomía e independencia al mismo tiempo que quiere mantener relaciones íntimas" (Albín, 2008, p. 24). Además, la relación que entabla el sujeto femenino con su entorno es contestaria, porque una de las principales causas por las que está llevando a cabo su proceso de independencia es, precisamente, la de contrarrestar las exigencias patriarcales impuestas por el padre y apoyadas por la sociedad en la que vive. A pesar de esto, "los conflictos a los que se enfrenta el personaje sí obstaculizan su desarrollo, que se presenta menos lineal, y comprometen su libertad y su autonomía” (Reyes Ferrer, 2018, párr. 8), aunque en algunos relatos, como en el caso de El prestigio de la belleza, la protagonista se ve impedida de ejercer su libertad y autonomía por factores externos, entre ellos la edad y el poder paternal, y solo al final logra un balance entre lo que se espera de ella por parte de su familia y la sociedad. En este punto del poder paternal se cumple a cabalidad uno de los parámetros que diferencian los dos tipos de Bildungsroman, el cual "se refiere a la diferencia del momento en la vida en que el hombre o la mujer deciden enfrentarse a la figura paternal o la edad en que empieza el bild’; en lo que respecta al Bildungsroman femenino, un parámetro adicional "consiste en que la mujer, además del proceso de encontrarse a sí misma, como en el masculino, tiene otro paso que es construir su propio lugar en el mundo" (Rosas Consuegra, 2017, p. 27). Dos hechos que se dan a cabalidad en la historia de Bonnett.

Otro aspecto del Bildungsroman femenino para resaltar es el de la religión y cómo

[...] opera en estas narraciones también como una "tecnología" dirigida a constreñir el cuerpo sexualizado de las protagonistas, controlando no solo su accionar erótico concreto, sino, especialmente, insertando su mandato en el espacio inasible del deseo. Vigilancia doble que apunta a capturar y codificar el cuerpo, pero también los excedentes que se resisten a la domesticación como es el espacio salvaje y multiforme de la fantasía (Eltit, 1997, p. эб1).

Esta situación se presta para que la subjetividad de la protagonista se rinda al statu quo sin replicar. A pesar de ello, cuando el sujeto femenino examina críticamente el mundo que la supedita, empieza su proceso de madurez.

Bonnett, como se estableció previamente, ha escrito dos textos que se destacan en particular por tener particularidades del Bildungsroman clásico y femenino. A cada uno le ha imprimido su sello personal, y de manera temeraria fue contra la norma al escribir un Bildungsroman sobre un personaje masculino siendo ella una mujer. 


\section{El prestigio de la belleza: entre la fealdad y la belleza del arte creativo.}

El prestigio2 "parece ser una autobiografía tan imaginaria como verídica y tan verídica como imaginaria al describir los itinerarios de una niña que se considera fea en una sociedad que suele celebrar la belleza"(Araújo, 2012, p. 337). En la novela la protagonista experimenta su crecimiento físico y psicológico con el convencimiento de que es "realmente fea", y por ende su "relato es, entre otras cosas, el de mis tratos con la belleza” (Bonnett, 2018a, p. 9). Desde el principio "La voz narrativa enuncia, explica y reitera la fealdad" (Araújo, 2012, p. 337) de la niña y a partir de esta premisa se crea un relato en el que si bien este tema es axiomático, se ve suplementado por todo aquello que le pasa a la protagonista a lo largo de su infancia y parcial adolescencia. Esta de la fealdad es una percepción que se presenta a menudo al lector no solo por las referencias que se hacen al respecto, sino porque la fealdad de la niña y su lucha por contrarrestarla se convierten en el arma para una historia de crecimiento y autoformación como ninguna otra. Uno de los martirios sufridos en la primera etapa de la vida de la protagonista es todo aquello que la madre, en cuya "familia la belleza era una constante", hace a lo largo de los años para que luzca agraciada de alguna manera,

[...] se dedicó a frotar mi tabique con manteca de cacao, a peinarme con agua de linaza y de manzanilla, a embadurnar la mancha de mi labio con un pegote de concha de nácar, a darme leche en cantidades colosales para dotar de calcio mis huesos. Todo aquel tratamiento tesonero se combinaba con batas de ojalillo, moños en la cabeza, zapatos blancos y diminutos aretes. Yo fui así altar, tótem, pastel, objeto sagrado frente al que mi madre se doblegaba con reverencia mientras untaba sus sales y bálsamos (Bonnett, 2018a, p. 13).

La fealdad es una máxima que pierde su vigor gradualmente cuando se da el "encuentro con un sentido de belleza presente en el arte creativo y su poder creador dando pie a un empoderamiento del personaje femenino a partir de la escritura" (Zamora-Breckenridge, 2018, p. 286). Al ver que sus esfuerzos por cambiarle el físico son infructuosos, la madre se entrega a la tarea de pulir "la inteligencia en bruto" que descubrió en su hija, y es así como bombardeó sus neuronas con "innumerables estímulos: a través de sus axones y dendritas mis células nerviosas recibieron, mucho antes de pisar un colegio, el impacto del Número y de la Letra Escrita" (Bonnett, 2018a, p. 18). De tal modo que cambia la manera en que la protagonista enfrenta su crecimiento a medida que descubre el mundo, a través de su arte crea-

A partir de ahora se referirá a la novela como El prestigio. 
tivo, su facilidad para el histrionismo y su carácter extrovertido. Su capacidad de leer y escribir a tan corta edad (antes de los 5 años) moldea la personalidad y las actitudes de esta joven, entre las que se destaca una rebeldía innata contra el sistema familiar en el que vive, que la lleva a cometer acciones que radicalizan su forma de pensar a medida que va creciendo. Un pensar producto de las expectativas estrictas que de ella tienen sus padres y de una mente creativa que alimenta a lo largo de los años con la lectura de todo tipo de textos, y muy particularmente de poesía. La protagonista toma en sus manos su proceso de autoformación en una sociedad y un sistema escolar que la oprimen, porque ella, al igual que otras protagonistas de Bildungsroman, "acquire self-knowledge, comprehend the true nature of the [...] socio cultural order in which they have to live as individuals" (Okuyad, 2011, p. 143). A diferencia de sus contrapartes masculinas, en las mujeres ese conocimiento se ve mediado por su género. Todo lo que ella recuerda de su crecimiento y sus acciones es narrado de manera fragmentada, pues

[...] la particularidad del Bildungsroman femenino es rememorar la vida pasada, pero no contada paso a paso, sino por fragmentos. Es un ir y venir en el tiempo, tal como ocurre con la memoria que es un vaivén de recuerdos sin un orden cronológico (Rosas Consuegra, 20II, p. 25).

Por un lado, El prestigio no solo cumple con este requisito, sino que lo hace conservando las edades definidas de la protagonista y en cada una de ellas deja ver lo que ha ido aprendiendo y descubriendo de la sociedad en la que vive; y por otro lado cumple con una de las premisas de los Bildungsroman en lo que "[a] regular development is observed in the life of the individual: each of the stages has its own intrinsic value and is at the same time the basis for a higher stage" (Boes, 2006, p. 232).

Por lo tanto, cada una de las edades aludidas en la narración refleja el descubrimiento de aspectos importantes en la vida de la protagonista, entre ellos la muerte, la tristeza, el miedo, el cortejo adolescente, la apatía por la religión y lo que esta representa, solo por mencionar algunos. El medio estilístico para transmitir estos hallazgos se vale de anacronías que marcan definidamente tanto el tiempo de la historia como el del relato, y ofrecen información sobre el asentamiento de ciertos rasgos de la personalidad de la protagonista que dejan ver cómo se forma su identidad. Tales anacronías están encadenadas entre sí por eventos, hechos que sucedieron en determinado momento en la niñez, que han marcado a la protagonista para bien o para mal, y se repitieron en la vida adulta de una manera similar, lo que 
la da a la historia una circularidad interesante al poner "en evidencia el sinsentido de la existencia, cuya consecuencia es el vivir rutinario y enajenado del hombre”, debido a que se "deambula por los intrincados corredores del mundo exterior, a través de un realismo cruento que visibiliza lo feo, sórdido y decadente de la realidad circundante" (Romero Carbonell, 2020, p. 16). Estas experiencias formativas son por lo general aquellas que la han mortificado de una manera u otra persistentemente, entre ellas, su "pelo debilucho" o el leitmotiv de su fealdad; en consecuencia, "mi identidad se reducía hasta el punto de hacerme dudar de mi propia existencia" (Bonnett, 2018a, p. 22). Pese a este hecho, su personalidad no se debilitó, por el contrario, "personalidad he tenido, en ocasiones incluso en exceso" (p. 22). La invisibilidad a la que se refiere la protagonista la ayuda a formarse en el ser que es en su edad adulta, porque desde "la infancia y la adolescencia, sin embargo, hice de la convivencia entre mi yo oculto y mi yo público todo un arte. [...] Aprendí a inflar el segundo como si fuera un globo de colores, y a reventarlo de manera estentórea”, mientras "el otro, el tembloroso, estaba siempre en silencio, midiendo, pensando, reflexionando" (p. 23). Estas etapas reflejan los conflictos vivenciales que se dan en las distintas épocas de formación de los seres humanos. Los de la protagonista de esta narración son abordados desde una edad particular a través de una mezcla entre la voz de la narradora adulta y el pensamiento de la niña en la edad aludida, ofreciendo ironía con humor, severidad con jocosidad, estableciendo por lo general su protesta contra el régimen reinante, sea este natural (lo que la vida y el destino le dieron) o social (lo que dan las normas instauradas en la sociedad). Este es en sí un recurso estilístico que se deriva del Bildungsroman femenino (Martínez, 1997, p. 132) con el cual Bonnett demuestra su maestría en el manejo del lenguaje retórico. Por ejemplo, con el tono riguroso de la edad adulta que se conjuga con la liviandad de la infancia se evidencia un aprendizaje, a veces implacable, que se ve apoyado en el uso del lenguaje típico de la edad referida. La ironía y el sarcasmo son más prevalentes en la edad adulta, mientras la sorpresa, las hipérboles y comparaciones son más propias de la infancia, porque

[...] es un diálogo, son voces que van y vienen sobre la existencia, sobre el trasegar del hombre por el mundo, el vivir que es sólo vivir si se emplea la palabra como espejo para mirarse. No hay nada más importante en la recuperación del tiempo que viajar al pasado y reencontrarse con el espacio de su infancia (Motato, 2013, pp. 38-39). 
En resumen, El prestigio trata entonces temas universales, pero desde el prisma de esta niña, que entre los cinco y los catorce años subvierte el orden, rompe las reglas, reta a sus mayores. Ella posee una claridad distinta del mundo que la rodea por la sensibilidad que le ha dado su vena creativa, esa misma en la que, según Díaz-Granados (2014), “el lenguaje permea[ba] las emociones humanas y las lleva[ba] a un ámbito de lo estético desde lo verdadero" (p.111), debido a que sus lecturas desde edad temprana le instilaron una madurez inusual y le facilitaron la sobrevivencia social y familiar.

Ahora bien, un aspecto interesante que se desgaja de esta novela, y que definitivamente la ubica en el Bildungsroman femenino, yace en las relaciones familiares, un sistema dominante que

[...] se presenta como el primer núcleo rector de la vigilancia y la gran demarcadora de los límites del cuerpo de las protagonistas, que oscilan afectivas y oblicuas entre un padre y una madre que inevitablemente - con mayor o menor énfasis - les proponen la perpetuación de modelos que resultan doblemente restrictivos (Eltit, 1997, p. эб1).

Modelos a los que la protagonista desde corta edad responde subvirtiéndolos y enfrentándolos pese a que el castigo la lleva a la enfermedad física (sufre de episodios de úlceras gástricas en diferentes etapas de su vida). Esto se debe a que su personalidad no es una de conformarse con la ley ni de hacer actos de contrición para redimirse; por el contrario, es una que objeta en tanto mecanismo de defensa. De ahí que su relación familiar más conflictiva es con el progenitor (al igual que en todo Bildungsroman masculino o femenino), a quien llama "[E]1 padre: el emperador, el califa, el rey de oros. Investido como estaba de toda autoridad, en sus manos estaba también el castigo. [...] Que nos cayéramos era algo que nos reprochaba, que lloráramos lo exasperaba" (Bonnett, 2018a, p. 58), y a quien considera una persona inflexible, severa, intransigente. Se convierte en una figura a la cual temerle, y por su misma naturaleza inaccesible se desea su atención, sus muestras de cariño, su comprensión: "Su mano en mi cabeza, sus dedos en mi mejilla, eran suficiente recompensa. [...] Su risa frente a nuestras gracias era como un montón de monedas cayendo entre el cuenco metálico que el sacristán pasaba los domingos" (p. 58). Al hecho de que su padre es un hombre de pocas demostraciones afectivas, demandante de su espacio y tiempo, se le suma que cumple a cabalidad el rol otorgado por la sociedad de ser el proveedor y protector de la familia, el que toma las decisiones; por ende, y por naturaleza para la protagonista, es la figura a la cual desafiar. Su proceso de rebeldía se exacerba por la 
relación inexistente que tiene con su padre. De él solo recibe órdenes, amonestaciones, castigos. No obstante, al ser el padre, "la voz de Dios" y representar el orden supremo, se creería que la madre es la encargada de balancear el orden de las cosas en la familia, pero en varias instancias, no es el caso. La figura de la madre se trastoca, ella surge "como trasmisora de la ley del padre (de la ley del sistema) que aparece nítida en estas narraciones como reproductora de los nudos hegemónicos"(Eltit, 1997, p. 561). De muchas maneras, la madre, más afectiva y consecuente que el padre, se transforma en la encargada de mantener el orden y dictar reglas en complicidad y apoyo del padre cuando es necesario. Son un equipo al cual la protagonista se enfrenta por igual porque entre ellos no hay división, son uno y el mismo: "adiviné que mi madre era la autora intelectual de la tortura que ahora me imponían. Siempre fue una mujer contenida, austera, con una voluntad de hierro" (Bonnett, 2018a, p. 110). Cuando la madre se torna en castigadora, cambia el dinamismo de la narración, y en momentos de la vida del personaje se pierde la esperanza en una justicia equitativa en su ambiente familiar. Uno de esos momentos es un parteaguas en la historia, pues en su preadolescencia, y después de haber infringido la ley en numerosas ocasiones y recibir muchos castigos en consecuencia, los padres deciden mandarla de interna a un colegio en la costa norte del país. Lo que parece castigo la protagonista lo toma como su libertad, y se traduce en el momento definitivo del crecimiento emocional e intelectual más significativo de la historia.

La separación de la familia, crecer lejos de ella, hacer un viaje, descubrir otro mundo son parámetros del Bildungsroman clásico. El viaje físico y emocional que emprende la protagonista de El prestigio le permite conocer otra manera de ver la vida, de ser tratada, de confirmar sus creencias, aumentar sus conocimientos y, sobre todo, de descubrir su vocación definitiva: la literatura. Es un despertar distinto al anterior. En este lugar vive experiencias que en su casa no hubiera vivido nunca. Es más, es en este último episodio de la narración donde se confirma todo lo que la historia ha ido cultivando a lo largo de las distintas etapas del crecimiento y rebeldía de la protagonista. Gracias a su estancia en el internado religioso, ella revalida su ateísmo - “en pocos días, como por milagro — valga la paradoja—, Dios quedó reducido en mi conciencia a una entelequia” (Bonnett, 2018a, p. 138)_, acepta su cuerpo y descubre su sexualidad — “a la hora de la ducha me di a la tarea de examinarme [...]. [A] la vista no encontré nada especialmente interesante. Con los dedos sí. Momentáneas dulzuras desconocidas, brevísimos espasmos divinos que, más prolongados, habrían producido ascensos 
místicos"(p. 136) - y experimenta el amor, al igual que el desamor, de una manera que la cambian - "en medio de la planta más bien humilde que hasta entonces yo había sido, comenzó a crecer una flor carnosa, llena de obstinación y osadía: una forma de reaccionar frente al amor que ya no iba a abandonarme nunca”(p. 188) - El internado la catapulta como una poeta y como una joven adolescente llena de intereses literarios que le otorgan "una experiencia rigurosa y completa, [donde] las variables de una taxonomía de recuerdos que retratan de una manera contundente lo más hondo de la condición humana y familiar" (Díaz-Granados, 2014, p. 112) le ayudan a enfrentar el mundo que había dejado atrás. Es también la última etapa de la historia donde se cierra el ciclo de un Bildungsroman femenino, que incorpora en su narración varios de los elementos que permiten incluirla dentro de la lista de este tipo de textos.

\section{Donde nadie me espere: de la libertad y la voluntad.}

En 2013 Piedad Bonnett publica Lo que no tiene nombre, una historia personal sobre el suicidio de su hijo menor, Daniel, ${ }^{3}$ que ofrece al lector una ventana para entrever lo que es vivir con una enfermedad mental devastadora tanto para el paciente como para la familia, la falta de comprensión sobre la misma, el dolor de la pérdida. Siguiendo con esta línea, en 2018 Bonnett publicó Donde nadie me espere, una novela que continúa con el tema de la enfermedad mental, esta vez desde la perspectiva de quien la sufre. Narrada en primera persona por Gabriel, un hombre de 31 años que se está recuperando de uno de sus últimos episodios de distimia, ${ }^{4}$ cuenta cómo ha vivido con una enfermedad que no sabe que tiene y que lo ha afligido desde corta edad. El terapeuta tratante de este último episodio lo incita a escribir su historia para de esa manera empezar una recuperación. Es a partir de este ejercicio de rememoración entre su infancia y el momento actual que esta novela se clasifica dentro de la categorización de Bildungsroman, pues el lector puede ver la coherencia existente en las experiencias vividas por Gabriel desde su niñez, siempre en busca de alcanzar la madurez de su espíritu atormentado por su enfermedad, hasta su errar por una Colombia violenta, oscura, sin esperanza. Se trata de una búsqueda, larga y autodestructiva, por una estabilidad mental y emocional mediada por la lectura. Gabriel es un lector voraz a quien

\footnotetext{
3 Daniel Segura Bonnett, el hijo menor de Piedad Bonnett, se suicidó el 14 de mayo de 2011. Sufría de esquizofrenia. Tenía 28 años recién cumplidos.

4 Trastorno depresivo crónico que puede ir acompañado de ansiedad.
} 
lo único que parece centrarlo en sus momentos más oscuros es la lectura y, eventualmente, la escritura. Es una historia de crecimiento y madurez que se atraviesa con el abuso del alcohol y la mendicidad en varios momentos. Aquí la concepción de fealdad se refleja en "el ajetreo propio del mundo moderno [en el cual] cobran protagonismo una serie de personajes derrotados y excluidos socialmente, según el código imperante en la época: borrachos, enfermos, depravados, lesbianas, drogadictos, mendigos, locos y asesinos" (Romero Carbonell, 2020, p. 17); un mundo por el que Bonnett siente una "solidaridad moral", ya que "siempre tuvo una inquietud por el indigente" (p. 22).

Con esta historia Bonnett confirma su compromiso por "la exigencia de hacer una crítica de la realidad social, de denunciar y rechazar sus más funestas manifestaciones, y la revelación de una realidad silenciosa mediante el lenguaje simbólico de la poesía" (p. 58) que una vez más se extiende a su narrativa. En esta ocasión el proceso de formación se da en conjunción con el uso de varias figuras literarias, entre ellas la hipérbole, la metonimia, y en particular, la analepsis - tras la que se regresa siempre al momento en el que el personaje está intentando superar su última recaída一, para hacer una crítica de la situación. A lo largo del recuento de Gabriel, el lector puede inferir cómo las muertes de su madre, cuando tenía once años, y posteriormente la de su hermana melliza, cinco años después, detonan el empeoramiento de su condición emocional. Por su parte, el padre, esa figura que en el Bildungsroman es tan protagónica como el personaje principal, en esta novela no decepciona, porque si bien no tiene confrontaciones directas con Gabriel, se caracteriza por su absentismo, más aún tras la muerte de la madre, deshaciendo así su paternidad; "cuando al final de la tarde regresó del entierro, su llanto me espantó. [...] Mi padre se olvidó de nosotros. [...] Elena [...] me daba besos en la mejilla. Ya desde mucho antes se había convertido en mi madre" (Bonnett, 2018b, p. 50). La ausencia paterna se equipara a la figura de un opresor, provocando un resentimiento desmedido en el protagonista, otro marcador de la historia, que lo impulsa a castigarlo con actos tan simples como afectar su economía: "Sabía que las finanzas domésticas no eran buenas, pero, con una crueldad que no me conocía, fui implacable y pedí el plato más caro de la carta” (p. 55), o tan extremos como abusar del alcohol y vivir en la calle. El abandono paterno se convierte en la relación de contención con el protagonista, un rasgo del Bildungsroman clásico.

En consecuencia, el camino recorrido por Gabriel presenta obstáculos creados por él mismo debido a su trastorno depresivo. La caracterización interna de este per- 
sonaje es la de un andar por el laberinto psicológico de una persona con problemas psiquiátricos que nunca fueron tratados. En su edad adulta, Gabriel es el producto de la falta de conocimiento sobre el tema por parte suya y de su familia. Una realidad que Bonnett conoce bastante bien debido a su experiencia personal, y se concentra en ella para incluir al lector en la batalla interna que vive su personaje. En este sentido la autora delineó la enfermedad de Gabriel desde la dialéctica de un espíritu con una necesidad intrínseca por la libertad: “dos semanas después me senté frente al escritorio de Morelli y le anuncié que el semestre siguiente no volvería a la universidad. [...] Quiero ser libre" (Bonnett, 2018b, p. 106). Puede presumirse que refiere a liberarse de su propia enfermedad, que lo hace delirar entre la sanidad y la locura, que lo sumerge en una espiral de decisiones erráticas, incontrolables. Tal modo de proceder, desencadenado por su voluntad espiritual de libertad, lo lleva a vivir experiencias que en su calidad profesor reemplazante de filosofía jamás habría tenido, entre ellas, ser vigía de una caleta de narcotraficantes, relacionarse con gente indigente y terminar al igual que ellos: "durante días y días fui apenas un animal que huía en las noches, entre matorrales primero, por caminos embarrados después, un animal que olía cada vez peor [...] que ya sobre el asfalto se hacía manso a la hora de pedir” (p. 183). Después de haber dejado su trabajo de profesor universitario para ir en busca de su anhelada libertad, esta se le presenta como un monstruo cuyo reino es la soledad: "nadie preguntó por mí en aquella temporada, y yo supe de una vez por todas que la libertad y la soledad van siempre de la mano" (p. 109). Los conceptos de libertad y soledad se ven mediados por los de la voluntad de saberse objeto de sus acciones y la razón, entes invisibles pero siempre presentes que hacen que Gabriel dude constantemente de los primeros. Los dos sentires compiten en la psique del protagonista y se retroalimentan. Bonnett legitima "las dimensiones del mundo, público y privado, desafía los límites sociales al sublimar lo no visible o no decible, como consecuencia de la lucha entre las normas sociales y la vocación de libertad entre el mundo y el yo" (Romero Carbonell, 2020, p. 20). Finalmente Gabriel se da cuenta que la libertad es la muerte. Pese a haber estado cerca de ella en muchas ocasiones, siempre escapó de la misma por motu proprio. Al final del día, el interés que siempre ha tenido por el suicidio no resulta ser más que una curiosidad.

Así pues, los sentidos de libertad y voluntad que se presentan en esta novela son, en consonancia con Hegel, dos conceptos que se complementan entre sí. La relación 
“entre voluntad y razón es esencial para comprender cómo y por qué Hegel piensa la actividad de la estructura de la voluntad, desde su primera determinación hasta la última, como libertad" (Flores-Miller, 2013, p. 20). A partir del convencimiento del personaje de ser libre, se puede hablar de cómo en esta narración se experimenta otro sentido del Bildungsroman que algunos académicos han mencionado, y que corresponde al término alemán Bildung, el cual se refleja como una "autoformación” en la que

[...] el sujeto individual, que parte de su consciencia sensible, tiene que recorrer el camino o devenir de la esencia en un proceso en el que, por el ejercicio dialéctico del saber, va construyéndose a sí mismo al mismo tiempo que ese saber, y puede llegar a realizar su esencia y descubrir la universalidad en sí mismo (Morgado, 2006, p. 184).

De acuerdo con Morgado, Hegel plantea "la experiencia que el sujeto sigue en su proceso lógico, una experiencia que recorre la elaboración de su saber", en la que cada individuo "debe realizar este proceso y en ello consiste su Bildung o formación que ha de producir en él una transformación" (p. 184). La experiencia vivida es parte de la formación individual del sujeto. Según la conceptualización hegeliana, "los conceptos de 'formación' o 'aprendizaje' hay que entenderlos como la apropiación progresiva que el Sujeto realiza del Objeto (Naturaleza, hábitos sociales, etc.), Objeto que conformado por el Sujeto, vuelve a él y lo constituye” (Rodríguez Fontela, 1996, p. 30), llevando más allá la definición literaria del Bildungsroman y acercando más el género a un carácter filosófico.

La novedad de la historia de Gabriel radica no solo en que Bonnett hace un guiño a la teoría fenomenológica hegeliana con la necesidad del protagonista de darle un sentido al sinsentido que es su vida, sino en la manera de hacerlo: es un afán, una voluntad irracional que lo lleva a vivir en los límites de su propia realidad, a enfrentar sus demonios internos con la autodestrucción, a ver el mundo como un lugar desolador y a las personas como entes insensibles e incompasivos. Este ejercicio constante del protagonista es otra faceta de la narrativa bonnettiana, extensión de su poética, en la cual

[...] la objetividad con la que retrata la realidad nace del equilibrio entre las categorías de lo abstracto y lo viviente, como resultado de la tensión lírica de la fuerza visionaria y reflexiva de una poesía [y narrativa en este caso] con ambiciones universales, pero anclada en una realidad inmediata (Romero Carbonell, 2020, p. 20).

Realidad en la que la indiferencia por el otro prevalece, demostrando la vacuidad de la sociedad en la que habita Gabriel. 
Voluntades semejantes a la de Gabriel logran que el sujeto haga un ejercicio de introspección mediante el cual se accede a un conocimiento esencial del "yo". Voluntad que "nace de la conciencia más inmediata de cada cual, donde uno conoce su propio individuo en su esencia, sin forma alguna, ni siquiera la de sujeto y objeto" (Schopenhauer, 2004, p. 133). Gabriel realiza dicho ejercicio cuando emprende el largo viaje desde Bogotá hacia la costa norte. El viaje, otro rasgo indeleble del Bildungsroman, que le permite conocer una Colombia agreste, donde la ley del más fuerte aún prevalece, al tiempo que le vislumbra lo que él mismo quiere, quién es y qué puede hacer para contrarrestar los impulsos interiores que lo tienen en el fondo emocional en el que se encuentra. La travesía y lo vivido en ella evidencian que las emociones son, en efecto, más fuertes que la razón. En su momento, Gabriel intentó darle un sentido a su vida, perseverar en su intento por ser alguien que puede llevar una vida normal con un trabajo ofrecido por su consejero universitario, quien le "propuso ser su asistente [...]. Me pagaban una suma decente, así que sin pensarlo mucho acepté todas las propuestas" (Bonnett, 2018b, p. 101); además entabló una relación amorosa con una joven que conoció en su trabajo temporal en la biblioteca, y comenzó a vivir lo que parecía ser una vida normal. Sin embargo, su voluntad, que maneja y lo maneja sin darle tregua, impide que estos intentos prosperen y, en cambio, lo avienta a un abismo que al final, y de una manera anómala, constituye su proceso formativo definitivo.

Con la experiencia vivida, intenta rehacer nuevamente su vida. Esta vez cuenta con que su volición es más fuerte, su conciencia de su verdad y del mundo en el que vive le ha ayudado a comprehender que esa libertad por la que luchó tanto, que logró con mucho esfuerzo, pero que también logró convertirlo en una ruina (Bonnett, 2018b, p. 152), le ofrece una segunda oportunidad cuyas reglas del juego son expresas, porque libertad en conjunción con voluntad hacen pasar por alto

[...] que el individuo, la persona, no es la voluntad como cosa en sí sino un fenómeno de la voluntad determinado ya como tal e introducido en la forma del fenómeno: el principio de razón. De ahí procede el asombroso hecho de que cada uno se considere a priori totalmente libre incluso en sus acciones individuales, y piense que a cada instante podría comenzar una nueva vida, lo cual significaría convertirse en otro. Solo a posteriori, a través de la experiencia, descubre para asombro suyo que no es libre sino que está sometido a la necesidad; que, pese a todos sus propósitos y reflexiones, su obrar no cambia y desde el comienzo al fin de su vida ha de mantener el carácter que él mismo desaprueba y, por así decirlo, tiene que representar hasta el final el papel que ha asumido (Schopenhauer, 2004, p. 135). 
Tal es el caso de Gabriel. A lo largo de la narración el lector puede ver que progresivamente el protagonista nota que su libertad está supeditada a lo que lo rodea, y que en realidad nunca fue preso sino de sí mismo. El ejercicio de escritura de Gabriel logra que el lector participe del proceso de autoformación, y comulgue o repudie las actitudes del protagonista, porque el Bildungsroman también tiene el propósito de hacer partícipe al lector de las experiencias vitales del protagonista, de impulsar al lector a la reflexión, a formar parte del debate ideológico ofrecido por el protagonista (Rodríguez Fontela, 1996, p. 44). Si bien la historia de Gabriel no se cierra al final, rasgo típico del Bildungsroman, deja la posibilidad de que el protagonista logre su autoredención. La novela es una historia de exploración psicológica, en la que las motivaciones internas y externas del personaje son el motor de sus acciones. Miedos, inquietudes, debilidades y fortalezas se exponen como parte de un todo que contribuye al crecimiento o aniquilación del personaje, e invitan al lector a identificarse o rechazar lo narrado, como se propuso anteriormente. En esencia, Gabriel es un personaje confeccionado para que los lectores reaccionen con su historia, pero también es la manera de Bonnett de solidarizarse con todos aquellos que sufren enfermedades mentales en una Colombia inerte. Su destreza radica en un uso apropiado del lenguaje, de imágenes que comulgan con los sentimientos de su personaje y con su solidaridad por "los seres marginados de la sociedad, de los que destaca su soledad y desamparo"(Romero Carbonell, 2020, p. 33).

\section{Conclusiones}

El Bildungsroman es una categorización teórica que "le ha proporcionado a toda la novela una base teórica y un extracto de su moderna idiosincrasia: el héroe que se hace a sí mismo en el combate con la realidad externa" (Rodríguez Fontela, 1996, pp. 33-34); además cuenta con una flexibilidad temática, estilística, de forma y género que ofrece una amplia gama de textos. En el caso colombiano varios son los autores que han recurrido a su uso, y Piedad Bonnett es ejemplo de la versatilidad del Bildungsroman. Entre ambas novelas existen similitudes y diferencias que se dan particularmente en la manera como se trata a los personajes y sus realidades. La autora delinea la psique humana de sus protagonistas con una carga psicológica indeleble: la depresión (Gabriel), la rebeldía (ella), un interés por el suicidio producto de las emociones y experiencias vividas por los protagonistas, por mencionar las más importantes. Es una visión dis- 
tinta de la condición humana, de la manera de ver el mundo, de los personajes al enfrentarse a sus verdades y miedos; una visión filosófica con ecos de las teorías de Hegel y Schopenhauer sobre la voluntad y el espíritu. A lo anterior se debe agregar que es narrado en un lenguaje directo, fluido, sin cabida para el sentimentalismo, "deliberado y artificiosamente sencillo" (Motato, 2013, p. 35), hecho que le da una agilidad a la narración en la que el lector puede disfrutar de la intelectualidad de los protagonistas, incluidas la lectura y la escritura como constante prevalente de Gabriel en Donde nadie me espere y de ella en El prestigio de la belleza.

Aunque el sujeto bonnettiano parte de experiencias como el dolor, la tristeza o la extrañeza (Romero Carbonell, 2020, p. 12), la realidad es que "un aliento desesperanzado atraviesa toda su obra en un movimiento marcado por el signo de la lucidez" (Cervera Salinas, 2014, p. 70). Bonnett logra con sus dos novelas conjugar el Bildungsroman con la realidad colombiana, que está siempre entre candilejas en los dos textos. Ese espacio físico e idealizado de la Colombia de antaño (El prestigio) y la actual (Donde nadie me espere) es parte intrínseca de las vidas de ella y Gabriel. Las dos narraciones muestran cómo la autora es recalcitrante con los temas que más parecen haber marcado su vida, a saber, la belleza, la depresión, la fascinación por el suicidio. Temas e historias que forman parte de un corpus literario que sigue vigente mundialmente y que Bonnett ha logrado recrear desde una perspectiva personal.

\section{Referencias bibliográficas}

Albín, M. C. (2008). El Bildungsroman femenino en Hasta no verte Jesús mío de Elena Poniatowska. América sin nombre. DOI: 10.14198/AMESN.11-12.07

Araújo, H. (2012). Dialogismo y espacio autobiográfico en Helena Arellano Mayz y Piedad Bonnett. Lingüística y Literatura 61, pp. 333-341.

Boes, T. (2006). Modernist Studies and the Bildunsgroman: A Historical Survey of Critical Trends.

Literature Compass 3 (2), pp. 230-243.

Bonnett, P. (2018a). El prestigio de la belleza. Bogotá: Debolsillo.

Bonnett, P. (2018b). Donde nadie me espere. Bogotá: Alfaguara.

Cervera Salinas, V. (2014). Voces plurales en la poseía de Piedad Bonnett. Rassegna Iberistica 37 (101), pp. 69-79. DOI 10.14277/2037-6588/4p

Cole, S. R. (2007). National Histories, International Genre: Thackeray, Balzac, and the Franco-British Bildungsroman. Romanticism and Victorianism on the Net 48. DOI: 10.7202/017436AR 
Danner, H. (1994). “Bildung”. A Basic Term of German Education. Educational Sciences 9. Recuperado de https://www.helmut-danner.info/pdfs/German term_Bildung.pdf [02.01.2021].

Díaz-Granados, F. (2014). Reseña de Las herencias de Piedad Bonnett. Boletín Cultural y Bibliográfico. XLVIII (86), pp. 111-112.

Eltit, D. (1997). Sobre María Inés Lagos. En tono mayor: relatos de formación de protagonista femenina en Hispanoamérica. Revista Iberoamericana 180, pp. 559-562.

Flores-Miller, G. (2013). El concepto de la voluntad libre en la Introducción a los Principios de la filosofía del derecho de G.W.F. Hegel. Pensamiento y Cultura 16, pp. 18-40.

Martínez, N. (1997). Reseña de En tono mayor: Relatos de formación de protagonista femenina en Hispanoamérica de María Inés Lagos. Chasqui 26, p. 131.

Morgado, N. (2006). La presencia de Schopenhauer y el Bildungsroman en Juegos de la edad tardía y El guitarrista de Luis Landero. Siglo XXI. Literatura y Cultura 4, pp. 183-200.

Motato, H. (2013). De la casa al universo en la poesía de Piedad Bonnett. La palabra 23, pp. 33-48.

Okuyad, O. (2011). Weaving Memories of Childhood: The New Nigerian Novel and The Genre of the Bildgunsroman. Ariel: A Review of English International Literature 41, pp. 137-166.

Reyes Ferrer, M. (2018). El Bildungsroman femenino: análisis de la novela de formación Un karma pesante. Acta Scientiarum: Language and Culture. DOI: 10.4025/actascilangcultv40i1.34611

Rodríguez Fontela, M. A. (1996). La novela de autoformación: una aproximación teórica e histórica al "Bildungsroman" desde la narrativa española. Oviedo: Reichenberger.

Romero Carbonell, M. (2020). La poesía de Piedad Bonnett. Dentro y fuera del laberinto. Madrid: Editorial Verbum.

Rosas Consuegra, A. (2017). Escritoras colombianas bajo la mirada del Bildungsroman como escritura de construcción de identidad: Marvel Moreno y Albalucía Ángel. La manzana de la discordia 2, pp. 23-34.

Schopenhauer, A. (2004). El mundo como voluntad y representación, I. Madrid: Trotta.

Zamora-Breckenridge, N. (2018). La fealdad como poder constructor en El prestigio de la belleza de la escritora colombiana Piedad Bonnett. En D. Martin, E. París y Y. Silva (Coords.). Agencia, historia y empoderamiento femenino (pp. 285-297). Santo Domingo: Ministerio de la mujer. 